\title{
Paling Posts
}

\author{
Martin Malloy \\ H Block 6, Long Kesh
}

Peter wasted no time alighting from the tractor and bounding down the slope at a gallop. Peadar Ned made heavy work of it. He chose his footing carefully, leading with his left foot and wedging the bill hook against tufts of grass before easing his trailing leg further down the incline. Both men had come prepared in their own way for the day's work. But only when Peadar Ned had found his footing at the bottom of the descent did he realise how unprepared he was for the sight ahead. He stared in at the hellish, black-charred devastation. He choked on the acid-like stench before covering his mouth with a large white handkerchief.

Peter had marched on ahead, indifferent it seemed to the rough uneven terrain or the burning smell. 'There's a job to be done,' he scornfully thought, glancing over his shoulder at the white flutter pin pointing the old man amidst the blackened forest and losing neither speed nor step as he did so. 'There was little point in calling back or in even waiting or the old man to catch up. It would evoke little response and less haste,' he contemplated. And so he tramped on.

Peadar Ned made steady progress now. He was a good thirty to forty paces behind the younger man, but even at that, he found himself wading through a storm of flaking black ash, which billowed in his wake. He wondered if some young entrepreneur wouldn't soon come up with an idea to market the stuff. 'Confetti Ash, the latest in funeral fashion.'

The figure ahead cut a strange shape as it swathed onward. The bright-red chain saw swung from side to side giving the appearance that he was slashing his way through the forest's undergrowth. Except there was no undergrowth worth mentioning. What was left of it crumbled into black powder at the slightest touch, making the presence of a chain saw seem ridiculous for the task in hand. The contrast between the yellowing barley field at home and this desolate place sent a cold shiver through him as he passed the rows of naked, black skeletons one after the other. 'What in God's name possessed anyone to do the like of this, "he was thinking when the scream of the engine cut across his line of thought.

Peter sent frail, charred, brittle branches flying in all directions. The chain saw roared again. Within seconds he had stripped the remaining branches from the trunk. The old man, only a short distance away now, looked at the lonely naked figure with its torn white flesh. But it was gone with one final scream, the cold steel ripping through the base of what had been a healthy young 
sapling. Another and another and another fell before the younger man looked around.

'Strip that lot tay yer left.' Peter nodded and turned back into his work. Peadar Ned removed his hat and large overcoat and carefully laid them on a high, dry spot, concealing beneath them a canvas shoulder bag. He licked his thumb and ran it over the gleaming bright edge of the bill hook. Satisfied, he made his way towards a group of prematurely balding young fir trees. He swung the hook over his left shoulder and cleaved off the highest branches with one clean swipe. As he went lower down, the impact jarred his wrists and shoulder. 'That was only to be expected, since the lower branches are thicker and I'm not yet warmed to the task,' he felt. He soon moved into a smooth methodical rhythm that wouldn't over tax him in the day ahead. He had only taken a few short breaks in the two hours or so, just to catch his breath and mop the sweat and dirt from his brow. But now that the younger man was speedily working up behind him, he felt he had to push on, regardless of the tiredness and pain he was feeling in his left arm.

'You may start piling those posts while 1 shoot down and get the tractor to bring a load out,' the younger man shouted, the chain saw not yet having time to fall silent. The old man turned to speak but looked into a black cloud of charred bark, resembling a swarm of flies, that the young man had just vanished from.

Peter practically raced across the bog. He knew there was a small fortune to be made, if only he could get the job done before the authorities sealed the place off. Peadar Ned obeyed the instructions and set about piling all the posts in a convenient spot for loading on to the tractor. He began by tossing the logs a short distance into the clearing, but as he moved along the row, his throw was falling short of the pile. It was extra work to have to lift the logs a second time in order to stack them properly. So he resigned himself to carrying them all the way. 'Two weren't so heavy,' he felt to begin with, 'If only his damned arm wasn't so painful. But he would take a rest and a bite of lunch soon after he finished the remainder on this side.' He carried a few more, single logs, this time on his right shoulder only. 'A bite to eat would replenish his strength,' he thought. He spread his coat on the heap of logs, to sit as he opened his bag. He put the bread to his mouth but felt no urge to eat it. 'Strange,' he thought, 'The country air usually gives a body a good appetite.' He caught the burnt smell in his nostrils and replaced the bread in its wrapping. 'Maybe a drop of tae will revive me,' he thought, pulling a tea-filled HP-sauce bottle out of a thick woolen sock, which kept it warm. He put it to his lips, 'Too warm, it's too warm to drink.' He felt up tight and ill-at-ease, as if his shirt was too tight on him, but he could find nothing wrong. He decided to rest himself hoping the discomfort would pass. 
As he lay back, he recalled the day's events: the dispute he had with Peter when he said he hoped the culprit that set fire to the forest would be caught, and that no good would come of anyone who'd profit from that sort of behaviour.

'Well! I'm not one for looking a gift horse in the mouth,' Peter had quipped, 'And sure, isn't it an ill wind that blows no good and I may as well have the posts before somebody else gets their hands on them,' he hurriedly added, in a bid, albeit in vain, to better his argument.

'There'll be wooden posts when we're dead and buried,' the old man concluded. All around the forest lay silent, not a bird nor even a breeze stirred. The place was deathly quiet and lifeless.

Peter stood rigid and cold as his grieving mother and family, clad in black, comforted one another. The bereaved watched on the burning scent of candle wax still in their nostrils as the priest blessed the coffin being supported over the open grave by two freshly cut paling posts. 